Cross Linguistic Transfer of Literacy Skills Between English and French Among Grade 1 Students Attending French Immersion Programs

$$
\begin{aligned}
& \text { Marie-France Côté } \\
& \text { Robert Savage }^{\text {b, c }} \\
& \text { Yaacov Petscher }^{\text {d }}
\end{aligned}
$$

aDépartement de didactique des langues, Faculté d'éducation, Montréal

Université du Québec à Montréal, Montreal,

\title{
Canada;
}

${ }^{b}$ Department of Educational Psychology, Faculty of Education, McGill University, Montreal, Canada;

${ }^{\mathrm{c}}$ Department of Psychology and Human Development, Institute of Education, University College London, London, UK;

${ }^{d}$ Florida Centre for Reading Research, Florida State University, USA 


\begin{abstract}
This study explored the impact of a supplemental reading intervention delivered in English in Grade 1 (Savage, Georgiou, Parrila, \& Maiorino, 2018) on the performance of at-risk children educated in French Immersion schools. The intervention contrasted 'Direct Mapping and Set-for-Variability' with a 'Common and Best Practices' taught control condition in a matched quasi-experimental design. To test claims of crosslinguistic transfer, measures of English and French word reading were administered before and after intervention. Hierarchical linear modelling analyses confirmed that children in the intervention condition showed improved performance at post-test on measures of English and French regular, exception, and pseudoword reading compared to the control condition. Intervention-specific cross language effects on French word and pseudoword reading shown here provide partial support for causal models of transfer in bilingual reading development.
\end{abstract}




\section{Cross Linguistic Transfer of Literacy Skills Between English and French Among Grade 1 Students Attending French Immersion Programs}

Learning to read in two or more languages characterises the experience of the majority of people in the world (Aronin \& Singleton, 2008; UNESCO, 2003). Any general theory of reading development must thus be able to explain such phenomena. Much research suggests a close association between word reading ability in children's first and second languages (Chung, Chen, \& Geva, 2018; Genesee \& Jared, 2008). Contemporary theoretical models of dual language development (e.g. Chung et al., 2018) consider transfer of learning to be a central construct. However, these models are based on correlational data. Intervention studies run in dual language contexts provide opportunities to test stronger and potentially causal claims about the influence of one language on progress in another (Savage \& Cloutier, 2017; Wawire \& Kim, 2018). To date, however, no studies have unambiguously demonstrated that growth in word reading as a result of intervention in one language is then reflected in growth in word reading for these same children in an additional language. We thus outline a study that seeks to meet this aim. Theories of dual language development are first briefly evaluated here before evidence from intervention is considered.

Theories of cross-linguistic transfer. There exists no consensus on the definition of transfer or the mechanism by which it operates (Savage \& Côté, 2019; Koda, 2012a). In the cross-linguistic literature, the term is generally considered as the positive (or negative) influence of one language on another (Kuo \& Anderson, 2010) and more precisely as the conscious or unconscious use of previous knowledge in one language when using another language. This indeterminacy is reflected in the existence of diverse 
models of transfer (Chung et al., 2018). The influential Developmental Interdependence Hypothesis (DIH, Cummins, 1979) suggests a set of non language-specific capacities support language and literacy development that, once developed in one language, are available to support the development of academic language in another language. The model predicts close L1-L2 correlations (Cummins, 2005; Genesee \& Jared, 2008) but does not however address how learning a majority versus a minority language as an L2 can influence cross-linguistic transfer (Côté, 2018). Recent models of transfer view it as complex and multiply determined. The 'Interactive Framework' (Chung et al., 2018) for example, views transfer of learning as influenced by cognitive and linguistic factors including L1-L2 distance, proficiency and language complexity, educational setting, and wider socio-linguistic and socio-cultural constraints.

Empirical research on transfer. The vast majority of studies investigating second language learning are cross-sectional and correlational (e.g. Chung et al., 2018; Snow, 2008). Studies demonstrate that strong correlations exist between L1 and L2 phonological awareness skills (e.g. Bialystok, McBride-Chang, \& Luk, 2005; Kruk \& Reynolds, 2012) and between L1 and L2 word and text reading skills in languages with similar orthographic systems (e.g. Genesee \& Jared, 2008; Melby-Lervåg \& Lervåg, 2011). Several studies have addressed the decoding ability of second language learners and showed that the development of those students' literacy skills is very similar to that of native-language learners (e.g. Lesaux, Koda, Siegel, \& Shanahan, 2006; Lesaux, Siegel, \& Rupp, 2007) and that the proportion of children experiencing difficulties in decoding is not higher in second language learners than in native-language learners (Chiappe \& Siegel, 1999). However, most of these studies focus on language-minority students learning to read English as a 
second language and who are educated in English. Therefore, those studies assess L2 instruction and L2 reading ability, not cross-linguistic transfer (Côté, 2018).

Few studies have used intervention as a method for exploring potentially causal cross-linguistic transfer. Goodrich, Lonigan, and Farver (2013) conducted an intervention study with 94 preschool Spanish-speaking students learning English to determine whether pretest scores in one language moderated the impact of the intervention on the other language at post-test. Students in the experimental conditions received four 20 -minute pull-out sessions per week teaching phonological awareness and print knowledge. In the first condition, instruction was given in English (L2) for 21 weeks. In the second, instruction was given in Spanish (L1) for nine weeks and then in English (L2) for the remaining weeks. Regression analyses showed a moderation effect of initial elision skills and vocabulary in one language on post-test scores for the same skills in the other language in both conditions. Thus, children with higher elision skills or vocabulary in one language benefitted more from the intervention in the other language at post-test than children with lower initial elision skills or vocabulary. No moderation effect was found for print knowledge or blending skills. The authors suggest that those results constitute partial evidence of transfer and that only certain emergent literacy skills transfer between languages.

Piper, Zuilkowski, \& Ong'ele (2016) report a literacy intervention targeting phonemic awareness, alphabetic principle, vocabulary, fluency, and comprehension with a large sample of multilingual first- and second-grade children in Kenya. Children who were taught English (L3) and Kiswahili (L2) showed significant improvement in L1 Mother Tongue (MT) reading outcomes of letter sound fluency, syllable fluency, and 
nonword fluency compared to controls, indicating the presence of transfer from L2/L3 to

L1 MT. Some caution needs to be attached to this study as controls strongly outperformed intervention groups at pretest. Demonstration of the full mediation of noninstructed outcomes by instructed language would, alongside main effects of intervention, provide the strongest causal evidence.

Vaughn et al. (2006) investigated the impact of a comprehensive literacy program focused on supporting emergent literacy, reading accuracy, fluency, and reading comprehension in 91 bilingual Spanish-English at-risk Grade 1 children in the U.S. Wawire \& Kim (2018) examined the impact of an eight-week small group intervention in phonological awareness and letter knowledge delivered in Kiswahili (L2) in Kenya. In both cases, there was evidence of transfer on phonological awareness and letter knowledge, but both are limited by not showing transfer of word reading ability.

In sum, some intervention studies' results suggest that phonological awareness skills transfer from one language to another following an effective intervention, but no intervention studies to date have unambiguously demonstrated that growth in word reading as a result of a well-designed and executed intervention in one language is then reflected in growth in word reading for these same children in an additional language compared to well-matched taught controls. We thus proceed to outline a study that seeks to meet this aim among Grade 1 students attending French Immersion programs.

\section{The present study}

The present study is nested within an existing published intervention. Savage et al. (2018) reported the results of a pan-Canadian study evaluating the impact of a preventative intervention carried out in English on the English reading skills of 201 at- 
risk elementary school students enrolled in French immersion programs in Quebec and Alberta, Canada. Students were assigned to one of two conditions. In the Common and Best Practices (CBP) intervention, children received systematic synthetic phonics and sight word instruction and shared book reading. In the Direct Mapping and Set-forVariability Intervention (DMSfV) condition children were taught grapheme-phoneme correspondences in the context of shared book reading (DM) and were also taught Setfor-Variability (SfV) strategies to match phoneme strings (e.g. 'ar'-'m', 'k'-'n'-'ee') to known regular and exception words (see Appendix A for a full description of the content of these interventions). Each group received a total of 11 hours of small-group instruction over 10 weeks. At-risk students in the DMSfV experimental condition performed significantly better than students in the CBP group $(p<.05)$ on English word reading and spelling at post-test and on English word reading and sentence comprehension at a delayed post-test in Grade 2. These results thus suggest that a preventative supplemental intervention teaching DM and SfV can help improve at-risk students' reading skills in L1.

All students in Savage et al. (2018) study attended French Immersion programs where they received instruction in both English and French. Within those programs, between 50\% and 100\% of instruction is provided in French. Participating children from Alberta lived in a province where English is the predominant language whereas the participating children from Quebec lived in a context where French is the predominant language. This latter context was thus seen as a fertile one for testing theories of crosslinguistic transfer. Within this language context, we explore the impact that the intervention in English had on the French reading proficiency of the participating English-French bilingual students in Quebec. It is particularly interesting to explore a 
context where children learn alphabetic languages that are both considered as having opaque orthographies because the mapping between phonemes and graphemes is not consistent in either language, albeit French reading is usually considered to be somewhat more transparent than English (Seymour, Aro, \& Erskine, 2003). Thus, based on the fact that similarities across languages support transfer (e.g. Kuo \& Anderson, 2010), it is possible to hypothesize that as French and English share orthographic opacity, strategic methods for successfully navigating this in one language may, in principle, transfer to the other. For example, when reading a variable vowel grapheme in English, the reader can try another known sound of the grapheme when the first attempt does not lead to a known word (e.g. when reading 'sparrow', trying out 'ow' like in "cow" or like in "low"). Given success with this strategy in English, the reader immersed in two spelling systems may apply broadly the same approach in a second language such as French (e.g. when reading 'preuve', trying out 'eu' like in "feu” or like in "peur"). On the other hand, a child who learns to read in a transparent orthography does not need to develop those strategies and will need to develop them when learning to read a more opaque language.

The linguistic context of Quebec also provides insight into specific issues concerning the way Set-for-Variability operates to support reading. Using phonics generally requires children to first correctly identify and then sequence letter-to-sound relationships such as Grapheme-to-Phoneme correspondences (GPCs). Recent "two-step models of word decoding” (Elbro, De Jong, Houter, \& Nielsen, 2012; Tunmer \& Chapman, 2012) identify a second step that is required for successful word recognition in phonics, after children have first correctly identified and sequenced GPCs. This second step is needed to blend a given string of phonemes and to then link it to an accurate 
assembled word pronunciation. This second step may require matching 'spelling pronunciations' derived from Grapheme-to-Phoneme correspondences (e.g. 'c'-'a'-'t'), to existing lexical entries in the mental lexicon (e.g. cat). This second step may thus require children to have a flexible mental "Set-for-Variability" because spelling pronunciations such as the accurate phoneme string 'c'-'a'-'t' (/ke/-/a/-/te/) derived from the first step of phonics bear only a relatively modest perceptual resemblance to a stored target word such as 'cat' (Elbro, De Jong, Houter, \& Nielsen, 2012; Tunmer \& Chapman, 2012). This mental flexibility may also be needed when trying to read exception words such as 'wasp'. The spelling pronunciation 'w'-'a'-'s'-'p' (/we/-/a/-/s/-/pe/) will require a mental flexibility to match it with 'wasp' (/wAsp/).

While SfV has been presented as a strategy more specifically deployed for mastering variable vowels in English (Steacy, Elleman, Lovett, \& Compton, 2016) or for 'mispronunciation correction' of regularized exception words (Dyson, Best, Solity, \& Hulme, 2017), Savage et al. (2018) have argued that given the modest overlap between a spelling pronunciation and a stored representation of any word, irrespective of a classification of it as 'regular' or 'exception' or as containing a variable vowel, SfV is best construed as a very general strategy for reading all words, at least among beginner readers. These views of SfV all see it as a mental process applied to phoneme strings and as 'teachable'. As such it might be predicted on most accounts that instruction in SfV in one language may impact development cross-linguistically, though the Dyson et al. (2017) and Savage et al. (2018) models differ on the specifics of whether they predict effects on regular versus exception words. 
Thus, the present research aims to answer the following research question: What are the impacts of a supplemental DMSfV intervention in English on the cross-linguistic transfer of phonological awareness and exception, regular and pseudoword reading skills in French among at-risk Grade 1 students enrolled in immersion programs?

\section{Method}

\section{Design}

This study, as well as the larger pan-Canadian study in which it is embedded, is a matched controlled intervention study with a pretest/post-test design. To avoid confounds that would be related to any sharing of information between the teachers or students in two different experimental conditions in the same school, schools, rather than classrooms or students, were randomly assigned to either DMSfV intervention or Common and Best Practices (CBP) control conditions. The choice was made to use an active control condition (CBP) rather than an untaught one in order to better evaluate the added value of the DMSfV condition. The sections below describe the participants, intervention and measures for the present study, but all methodological aspects of the larger pan-Canadian study are described in Savage et al. (2018).

\section{Participants}

The present cross-linguistic investigation research in French took place only with Grade $1(n=84)$ at-risk students, in the 2014-2015 school year in Montreal (Quebec). These students were selected from an initial sample of 226 children recruited from 10 public French Immersion elementary schools in Greater Montreal. All participants in the study attended French Immersion programs, which divided instructional time more-or-less equally between English and French (See Appendix B for details). In the present sample, 
parent reports suggested that $72.1 \%$ of the Grade 1 students spoke English at home with at least one of their parents and $61.6 \%$ spoke English with both their parents. Only $29.1 \%$ of the Grade 1 students spoke French with at least one of their parents and 19.8\% spoke French with both their parents. Only 8.1\% of the students spoke neither French nor English at home. Therefore, for the sample as a whole, English can be viewed as the main home language for most of the students and French as a second language. Details concerning participants' demographics can be found in Table 1. The students involved in this research all came from regular public elementary schools in Greater Montreal. Girls represented $52.5 \%$ of the sample.

In the present study, all Grade 1 students scoring below the $30^{\text {th }}$ percentile on the WRAT IV English word-reading measure at pretest were considered at-risk. No at-risk participant was excluded from the project. Before at-risk students were identified, schools were randomly allocated to either the $\operatorname{DMSfV}(n=3)$ or the CBP $(n=5)$ condition. Children participated in the small-group intervention to which their school was first assigned: DMSfV $(n=52)$ or CBP $(n=32)$. The variation in sample size reflects the schoollevel randomization and screening.

\section{Materials}

Student performance in English and French word reading was assessed at pretest (December) and post-test (May) immediately before and after the intervention to investigate cross-linguistic transfer. The English tests were: The reading subtest of the Wide Range Achievement Test III (WRAT), 20 words from the Fry high frequency word list, the nonword segmentation subtest of the Comprehensive Test of Phonological Processing (CTOPP) and the segmentation fluency and spelling subtests of the Woodcock- 
Johnson III Test of Achievement (WJ). Details concerning these measures can be found in Savage et al. (2018).

There exist very few tests in French, either standardized or unstandardized (Desrochers, DesGagné, \& Kirby, 2011). Therefore, students' performance in French on word reading (irregular words, regular words and pseudowords) was assessed through standardized and experimental measures. Part of the tests that were used to measure French were taken from the standardized test battery "Épreuves de Compétence en Lecture (ECOLE)" developed by Professor Alain Desrochers from the University of Ottawa. In the present research, the measures of phoneme blending, exception word and regular word reading of the "ECOLE" battery were used and are described below.

Lamarche and Desrochers (2016) examined the concurrent validity of the "ECOLE" word lists with the word reading tests from the "Batterie d'Évaluation du Langage Écrit (BELEC)" (Mousty, Leybaert, Alegria, Content, \& Morais, 1994), a widely used standardized test for the French language. Correlations were high between the regular word tests $(r=.83)$ and irregular words tests $(r=.81)$, indicating that both tests measure very similar constructs.

ECOLE Standardized measure of phonemic awareness. This test assesses students' ability to blend between two and seven phonemes in order to produce a word (e.g. /s/-/k/-/i/ makes "ski"). This subtest contains 3 training items, 20 regular test items $(\alpha=.88)$ and takes approximately 5 minutes to complete. The 20 items systematically progress on the basis of word length and syllabic structure complexity. For each item, the examiner pronounced a sequence of separate phonemes and then asked the student to identify the word that was composed of those phonemes. The test was discontinued if the 
student obtained a score of 0 on four of six consecutive items. The Spearman-Brown split half internal reliability in this sample was $r=.92$.

ECOLE Standardized measures of word reading. This measure contains separable regular and irregular word lists. In both the regular and irregular words list, 36 items were selected to progress in terms of word length and frequency. The list of regular words contains only words constructed from simple graphemes (single letter graphemes) and that follow orthographic patterns that are regular in French (e.g. problème, vérité, brume). Items on the irregular word list were selected to contain at least one inconsistent GPC in French (e.g. pied, dix, doigt). For both lists, the examiner presented a page with a group of four words and asked the student to read all words from the top of the page to the bottom. The test was discontinued if the student provided 4 incorrect answers within 6 consecutive words. The Spearman-Brown split half internal reliability in this sample was $r=.97$ for the list of regular words and $r=.95$ for list of the irregular words.

Experimental measures of pseudoword reading. An experimental list of 30 pseudowords was also used to assess participants' ability to decode specific GPCs and was developed by the current author. 12 pseudowords were built with simple graphemes (e.g. 'nème', 'lènade') whereas the other 18 also contained pseudowords with complex graphemes (e.g. 'linta', 'fimeau'). The words were built with simple syllabic structures (e.g. CVC, CCV, etc.) and frequent GPCs (e.g., 'en', 'ou', 'on', 'au'). The test lasted approximately 10 to 15 minutes. The Spearman-Brown split half internal reliability in this sample was $r=.93$.

Classroom environment. The Early Language and Literacy Classroom Observation (ELLCO) (Smith, Brady, \& Clark-Chiarelli, 2008) was used to assess the 
quality of the classroom environment and teachers' literacy practices in French, and to establish that the two interventions were matched on overall teaching quality. Two observations were undertaken in the school year (November and May). Analyses of interrater reliability of all class observations showed very high agreement of $97 \%$ on Classroom Structure, 99\% on Learning Environment, 99\% on Curriculum, 98\% on Books and Reading, and 96\% on the Print and Writing subtests of the ELLCO.

\section{Interventions}

The two interventions that are presented in this study were researcher designed and consisted of three 30-minute out-of-class sessions per week for around 11 hours run by trained RAs with groups of three to four children. The DMSfV approach consisted of (a) focus on GPCs including variable vowel pronunciations within a synthetic phonics model; (b) very close linkage between grapheme-phonemes taught and shared reading of real books containing a high density of exemplars of that digraph; (c) the teaching of 'setfor-variability' to map spelling pronunciations of words; and (d) significant differentiation of the curriculum. The CBP approach was characterized by (a) intense systematic focus especially on blending and, later, segmenting phonemes within a synthetic phonics model; (b) daily teaching of common sight words pronunciations and shared book reading and (c) the absence of close linkage between grapheme-phonemes taught and shared reading of real books, the absence of teaching of set-for-variability, and systematic strategy for variable vowel digraphs. All other nonspecific aspects of intervention delivery were comparable to the DMSfV intervention. A complete description of both interventions can be found in Appendix A.

\section{Results}




\section{Preliminary Data Analyses}

All data were first screened for the presence of deviations from normality, homogeneity of variance and outliers. No significant problems in the data distributions (i.e., skew, kurtosis, heteroscedasticity) were detected. Analysis also showed there was less than 5\% (1.94\%) data missing and Little's MCAR test showed missing data could be considered missing completely at random: $\chi^{2}(61)=49.07, p=.864$.

Prior to analysis, the quality of match on a range of variables between participants of both conditions was assessed for the variables reported in Table 1. Comparison of categorial responses here was undertaken using $\chi^{2}$. Effect sizes were calculated through Cramers' V. Results showed that fathers' L1 was more often English and English was used more often by fathers with their child in DMSfV. Mothers' education was also higher in DMSfV. None of the other variables (gender, mothers' L1, mothers' language spoken to child, and learning disability) were significantly different between groups, showing that the two conditions are matched on many important extraneous variables.

ANOVAs were also conducted to compare teachers' practices in both experimental conditions (i.e. DMSfV, CBP). Results revealed that no significant differences $(p>.05)$ existed between the experimental groups at Time 1 or Time 2 . Teaching practices in both conditions were considered equivalent and were unlikely to be confounding variables.

\section{Results of the small-group intervention}

The means and standard deviations for each intervention condition at pre- and post-test, as well as effect sizes at pretest can be found in Table 2 for English measures and in Table 3 for French measures. It is noteworthy to mention that groups were not equivalent for the French pretest, since they were systematically matched only on the 
basis of English word reading measures (Savage et al., 2018). Inspection of the data also suggests an advantage for the DMSfV group on all French measures at post-test.

Preliminary unconditional models revealed dependency (students nested within classrooms) in the data. ICCs are reported in Tables 4 and 5. Hierarchical linear modelling (HLM) was thus appropriate. Here, a two-level model was hypothesized modelling level 1 student's scores and level 2 classroom mean scores. Predictors were experimental (DMSfV) versus control (CBP) condition and labelled 'Intervention' in Tables 4 and 5, and respective level 1 and 2 pretest scores. The latter potentially adjusts for pre-intervention differences. Classrooms, not intervention small groups, were the level 2 units since students' intervention group membership varied during the study.

\section{Results of preliminary analyses for Grade 1 at-risk students in English}

Since our research question relates to cross-linguistic transfer, it was important to first consider how the students responded to the intervention in the language in which it was conducted. If, after an intervention in English, no improvement can be observed in the English reading scores (close transfer), it is then less likely that any improvement in French (far transfer) is due to cross-linguistic transfer. The WRAT word reading and the WJ-III Pseudoword reading were identified as primary outcome measures, as they were the tasks more closely reflecting the content of the small-group interventions. Unadjusted alpha of $p<.05$ was thus used for these measures. All other measures were considered secondary outcomes and alpha adjustments were made for the total number of secondary outcomes ( $\alpha$ $=.05 / 3=.02$ at post-test). The results of these analyses are reported in Table 4 . The results of the analyses of student performance in English for the Quebec-only sample are similar to the ones reported by Savage et al. (2018) for the pan-Canadian sample: they show a 
significant difference between groups at post-test in favour of the DMSfV group for the WRAT word reading, with a large effect size $(d=0.69)$. No other significant differences are observable at post-test considering the adjusted alpha of $p<0.02$. Small to medium effect sizes can be observed across all other English outcomes, as can be seen in Table 4 .

\section{Results of preliminary analyses for Grade 1 at-risk students in French}

Measures of irregular and regular word and pseudoword reading in French were considered to best reflect the work undertaken in the small-group interventions and were thus set as primary outcome measures $(p<.05)$. All other measures were considered secondary outcomes and alpha adjustments were made for the total number of secondary outcomes $(\alpha=.05 / 2=.025)$. For the irregular word measure, the HLM models with pretest in the model did not converge, because of floor effects at pretest. Therefore, results of analyses without pretest are reported for this variable only. The results of the final HLM models depicted in Table 5 show that there are significant differences between groups at post-test, as well as large effect sizes for the irregular $(d=0.96)$, regular $(d=0.65)$, and pseudoword $(d=0.73)$ reading primary outcomes in favour of the DMSfV group $(p<.05)$. There are also significant differences between groups for all other French outcomes, also favouring the DMSfV condition $(p<.025)$. As can be seen in Table 5, medium to large effect sizes can be observed across all measures in favour of the DMSfV condition.

\section{Discussion}

The present study sought to evaluate the impact of a preventive literacy intervention in English on cross-linguistic transfer of French literacy skills of at-risk Grade 1 students enrolled in French Immersion (French/English) bilingual elementary schools. The HLM analyses showed that students in the DMSfV intervention performed consistently better at 
post-test in both English and French. The concordance between the results of the analyses in English and French provides preliminary evidence of cross-linguistic transfer. Significant improvements were observed in word reading in English and in French for the DMSfV condition over the CBP control condition only at post-test, despite the fact the intervention was delivered only in English, and where the most obvious confounds such as quality of teaching (i.e. directly-observed regular classroom teaching) did not differ significantly. Improvement in French was observed immediately following the intervention, suggesting that transfer was immediate. These findings are in line with previous correlational research indicating the presence of a strong relationship between L1 and L2 phonological awareness (e.g. Kruk \& Reynolds, 2012) and word and pseudoword reading skills (Bialystok, Luk, \& Kwan, 2005; Snow, 2008).

The strongest main effect we report was for irregular words, which suggests that students did use, and benefit from the SfV element in particular within the program. Other work (Savage, Georgiou, Parrila, Côté, Maiorino, \& Dunn, 2020; Savage, Georgiou, Parrila, Maiorino, Dunn, \& Burgos, 2020) shows that DM delivered alone aids reading only for children with stronger phonological awareness in English. Different children with different L1 and L2 language skills may however use the intervention content and these untaught but required syntactic, semantic, and phonological resources to varying degrees in generalising to French. The DMSfV intervention was also not designed to favour cross-linguistic transfer, taught no strategies for transfer, and indeed involved no reference whatsoever to French in its delivery.

Our first results showing main effects of intervention in English on French outcomes are, however, partly consistent with and, we cautiously claim, extend 
knowledge. Previous well-executed intervention studies in bilingual contexts have suggested that intervention may lead to transfer of phonological awareness and letter knowledge in untaught languages (Vaughn et al., 2006; Wawire \& Kim, 2018), suggesting cross-linguistic transfer. The present study provides the first preliminary evidence that such effects may also be evident for word reading. Our study does not include a "business as usual" control condition. However, the use of a taught control group is arguably a strength of this study as the DMSfV intervention was compared to an intervention (CBP) based on methods that have been repeatedly shown to be effective in the literature. Moreover, teachers of French and English classes were different in every school, which adds to the strength of the claim as cross-linguistic transfer is not likely due to the teaching practices of one single teacher. Future work could usefully explore the impacts of DMSfV in a three-arm trial also including an untaught control.

The results may suggest that the distinct content and the teaching methods that were part of the DMSfV intervention provided a learning environment that, overall, fostered immediate transfer. Effects cannot be driven by provision of systematic synthetic phonics or shared book reading, as these were all provided in the CBP condition. We cannot determine which of DM and SfV is the origin of students' superior performance in the DMSfV condition. Savage et al. (2018) note that the stronger effects for words over pseudowords in English suggests that SfV influenced outcomes. Theoretically, multiple lexical knowledge sources (phonological, orthographic, semantic) are needed to read proficiently in opaque orthographic systems such as English. Triangle models view these knowledge sources to be highly connected and interactive (e.g. Dyson et al., 2017; Plaut, McClelland, Seidenberg, \& Paterson, 1996). Thus, it may be this multi-component 
teaching, rather than only one of the distinctive aspects of the DMSfV, that led to significantly better reading in English and in French among students in this condition. Future work will be needed to more-precisely evaluate the impact of each strategy or their combination on L1 outcomes and cross-linguistic transfer.

The present results do, however, speak to the nature of SfV in a more specific sense. As noted earlier, one view of $\mathrm{SfV}$ is as a strategy for mastering variable vowels in English (Steacy et al., 2016). Children in the DMSfV condition showed transfer effects in French. This result cannot be due to the use of strategies for reading variable vowels for two main reasons: 1) there were no French complex variable vowels GPCs in the French regular word list and only very few in the pseudoword task ('eu' and 'e' in only three items, e.g. 'leudu') and the irregular word list ('eu' and 'e' in only two items, e.g. 'vert'); 2) the variable vowels GPCs that were taught in English could be found in the French pseudoword task and regular and irregular word lists. However, in French, those vowel GPCs are not variable and map onto only one phoneme (e.g. 'ou' only maps to /u/ in French whereas in English it can map to either the sound in 'mouse' or in 'shoulder'). The finding of transfer effects for all French tests is consistent with the view of SfV as a strategy for reading all words. The larger effects for exception words might also suggest children are using SfV for 'mispronunciation correction' (Dyson et al., 2017), though comparisons of outcomes by word types require great caution given differences in measurement and analysis here.

\section{Limitations and contextualisation}

A number of additional limitations should be noted. The present study, with a sample of 84 students is smaller than would have been desirable for the HLM analyses. The fact that significant differences were found between groups alongside moderate 
effect sizes following the intervention relative to word reading, even with this sample, suggests that the study was sufficiently powered to detect such effects and that these effects are substantial, and potentially practically important. Some statistically significant demographic differences existed between groups, namely mothers' education and fathers' first language, favouring the DMSfV condition, so some caution in interpretation is needed. However, groups did not differ on key variables of gender, mothers' L1 and language spoken to child, LD diagnosis, or observed classroom teaching practices. The study did not include a "business as usual" control condition, a contrast that awaits study. However, a taught control used here also controls for possible Hawthorne effects from supplemental researcher-delivered intervention. Finally, standardized tests in French are still few in number (Cormier, Desrochers, \& Sénéchal, 2006). In the present research, the ECOLE battery, designed to evaluate Quebec students' French reading, was used as well as an experimenter-created measure of French pseudoword reading. In English, the WRAT and the Woodcock Johnson pseudoword subtest were used, so constructs are not identical across languages. Moreover, the ECOLE is not fully standardized. Future research should use standardized tests of identical literacy constructs in both languages where possible.

The present study explored transfer from a majority L1 English language intervention to minority L2 French outcomes for children in French Immersion schools in Quebec, Canada. The particularities of this context are potentially relevant to model development. Quebec is officially a French-language province. In the wider culture, there is a high degree of ambient French. As a group, the English minorities in Quebec do not experience the political, cultural, and socio-economic challenges of Spanish L1 students 
in the United States or English L2 or L3 learners in Africa, the samples in previous crosslinguistic transfer intervention studies (Vaughn et al., 2006; Wawire \& Kim, 2018). In addition, English and French orthographies share a high degree of structural similarity, share significant amounts of content (e.g. numerous 'cognates') and are both considered opaque orthographies (Schmalz, Marinus, Coltheart, \& Castles, 2015). Considering the multiple-component 'Interactive Framework' (Chung et al., 2018), transfer of learning is influenced by factors including L1-L2 distance, proficiency and language complexity, educational setting, as well as wider socio-linguistic and socio-cultural constraints. All of these features may be present to facilitate transfer in the Quebec French Immersion context, in a manner that may not exist in some other bilingual contexts.

\section{Conclusions and implications for practices and policy}

The pattern of results observed in the present study provides some evidence of cross-linguistic transfer. Results of HLM analyses provide evidence that, in early grades, explicit and systematic phonics instruction including the teaching of systematic phonics delivered in the context of real books that richly embody taught GPCs, along with teaching of SfV strategies, can support cross-linguistic transfer from English to French. Replication of these basic findings is important in larger samples, and further intervention work with mediation analyses in such large sample studies is also clearly warranted. With such evidence in hand, these practices could potentially be adopted in the context of Grade 1 teaching in French Immersion programs as evidence-based practice to prevent the development of reading difficulties.

In summary this study is, to our knowledge, the first well-matched intervention study with a taught control in the literature to investigate and provide information regarding 
cross-linguistic transfer for multiple word reading outcomes and among at-risk students. The results of the present study do not firmly establish causal links and require replication but represent an important step towards a better understanding of the causal mechanisms supporting cross-linguistic transfer of reading and of the nature of the knowledge being transferred.

\section{Acknowledgments}

This work received approval from the McGill University Research Ethics Board Office (REB \# 458-0612- Responding to intervention: schools where all children are taught to read), and was executed in full accordance with McGill University policy and the Canadian Tri-Council Policy Statement Ethical Conduct for Research Involving Humans. All participants (or their legal guardians) gave their informed consent and children gave their assent prior to their inclusion in the study.

We would like to thank the teachers, principals and students of the English Montreal, Sir Wilfrid Laurier, Lester B. Pearson, and Riverside School Boards, Montreal, Quebec, Canada.

\section{Conflict of interest}

There is no conflict of interest reported for any of the authors involved in this work.

\section{Funding}

This work was supported by the Max Bell Foundation; Social Sciences and Humanities Research Council of Canada [435-2012-0164] 


\section{References}

Aronin, L., \& Singleton, D. (2008). Multilingualism as a new linguistic dispensation. International journal of multilingualism, 5, 1-16. doi:10.2167/ijm072.0

Bialystok, E., Luk, G., \& Kwan, E. (2005). Bilingualism, biliteracy, and learning to read: Interactions among languages and writing systems. Scientific Studies of Reading, 9, 43-61. doi:10.1207/s1532799xssr0901_4

Bialystok, E., McBride-Chang, C., \& Luk, G. (2005). Bilingualism, language proficiency, and learning to read in two writing systems. Journal of educational psychology, 97, 580-590. doi:10.1037/0022-0663.97.4.580

Chiappe, P., \& Siegel, L. S. (1999). Phonological awareness and reading acquisition in English-and Punjabi-speaking Canadian children. Journal of Educational Psychology, 91, 20-28. doi: 10.1037/0022-0663.91.1.20

Chung, S. C., Chen, X., \& Geva, E. (2018). Deconstructing and reconstructing crosslanguage transfer in bilingual reading development: An interactive framework. Journal of Neurolinguistics. doi: 10.1016/j.neuoling.2018.01.003

Cormier, P., Desrochers, A., \& Sénéchal, M. (2006). Validation et consistance interne d'une batterie de tests pour l'évaluation multidimensionnelle de la lecture en français. Revue des sciences de l'éducation, 32, 205-225. doi:10.7202/013483ar

Côté, M.-F. (2018). Cross-Linguistic Transfer of Literacy Skills Between English and French Among Grade 1 and 2 Elementary School Students attending French Immersion Programs. [Unpublished doctoral dissertation]. McGill University. 
Cummins, J. (1979). Linguistic interdependence and the educational development of bilingual children. Review of Educational Research, 49, 222-251. doi:10.3102/00346543049002222

Cummins, J. (2005). Teaching for cross-language transfer in dual language education: Possibilities and pitfalls. Paper presented at the TESOL Symposium on dual language education: Teaching and learning two languages in the EFL setting, Bogazici University, Istanbul, Turkey. Retrieved from http://www.achievementseminars.com/seminar_series_2005_2006/readings/tesol.t urkey.pdf

Desrochers, A., DesGagné, L., \& Kirby, J. R. (2011). L'évaluation de la lecture orale. In M.J. Berger et A. Desrcohers (Eds.). L'évaluation de la littératie, (pp.177-214) Ottawa: Les Presses de l’Université d'Ottawa.

Dyson, H., Best, W., Solity, J., \& Hulme, C. (2017). Training mispronunciation correction and word meanings improves children's ability to learn to read words. Scientific Studies of Reading, 21(5), 392-407.

Elbro, C., de Jong, P. F., Houter, D., \& Nielsen, A. M. (2012). From spelling pronunciation to lexical access: A second step in word decoding?. Scientific Studies of Reading, 16(4), 341-359.

Genesee, F., \& Jared, D. (2008). Literacy development in early French immersion programs. Canadian psychology, 49, 140-147. doi:10.1037/0708-5591.49.2.140

Goodrich, J. M., Lonigan, C. J., \& Farver, J. M. (2013). Do early literacy skills in children's first language promote development of skills in their second language? 
An experimental evaluation of transfer. Journal of educational psychology, 105, 414-426. doi:10.1037/a0031780

Koda, K. (2012a). Development of second language reading skills: cross-linguistic perspectives. In S. M. Gass \& A. Mackey (Eds.), The Routledge Handbook of Second Language Acquisition (pp. 303-318). Oxon: Routledge.

Kruk, R. S., \& Reynolds, K. A. A. (2012). French immersion experience and reading skill development in at-risk readers. Journal of Child Language, 39, 580-610. doi:10.1017/S0305000911000201

Kuo, L.-J., \& Anderson, R. C. (2010). Beyond cross-language transfer: Reconceptualizing the impact of early bilingualism on phonological awareness. Scientific Studies of Reading, 14, 365-385. doi:10.1080/10888431003623470

Lamarche, J. \& Desrochers, A. (2016). L'analyse psychométrique d'une batterie d'épreuves conçue pour évaluer les habiletés en lecture chez les élèves de 5 à 8 ans. Unpublished manuscript, Faculté des sciences sociales; École de psychologie, Université d'Ottawa, Ontario, Canada.

Lesaux, N. K., Koda, K., Siegel, L. S., \& Shanahan, T. (2008). Development of literacy. In D. August \& T. Shanahan (Eds.), Report of the National Literacy Panel on language-minority children and youth : acquiring literacy in a second language (pp. 27-60). Mahwah, NJ: Lawrence Erlbaum.

Lesaux, N. K., Siegel, L. S., \& Rupp, A. A. (2007). Growth in reading skills of children from diverse linguistic backgrounds: findings from a 5-year longitudinal study. Journal of Educational Psychology, 99, 821-834. doi: 10.1037/00220663.99 .4 .821 
Melby-Lervåg, M., \& Lervåg, A. (2011). Cross-linguistic transfer of oral language, decoding, phonological awareness and reading comprehension: a meta-analysis of the correlational evidence. Journal of research in reading, 34, 114-135. doi:10.1111/j.1467-9817.2010.01477.x

Mousty, P., Leybaert, J., Alegria, J., Content, A., \& Morais, J. (1994). BELEC : Une batterie d'évaluation du langage écrit et de ses troubles. In J. Gregoire \& B. Piérart (Eds.), Évaluer les troubles de la lecture: Les nouveaux modèles théoriques et leurs implications diagnostiques (pp. 127-145). Bruxelles: De Boeck.

Piper, B., Zuilkowski, S. S., \& Ong'ele, S. (2016). Implementing mother tongue instruction in the real world: Results from a medium-scale randomized controlled trial in Kenya. Comparative Education Review, 60, 776-807. doi:10.1086/688493

Plaut, D. C., McClelland, J. L., Seidenberg, M. S., \& Patterson, K. (1996). Understanding normal and impaired word reading; Computational principles in quasi-regular domains. Psychological Review, 103, 56-115. doi: 10.1037/0033-295X.103.1.56

Québec (Province). (1977). Bill 101: Charter of the French Language. Quebec: C.-H. Dubé.

Savage, R., \& Cloutier, É. (2017). Early Reading Interventions: The state of the practice, and some new directions in building causal theoretical models. In K. Cain, D. Compton \& R. Parrila (Eds.), Theories of reading development (pp. 409-436). Amsterdam, The Netherlands: John Benjamins.

Savage, R., Georgiou, G., Parrila, R., \& Maiorino, K. (2018). Preventative reading interventions teaching direct mapping of graphemes in texts and set-for-variability 
aid at-risk learners. Scientific Studies of Reading, 22(3), 225-247.doi:

10.1080/10888438.2018.1427753.

Savage, R. \& Côté, M.-F. (2019). The teaching of reading and writing in second and multi-language contexts: evidence from Canada. In International Bureau of Education (IBE-UNESCO) (Ed.), Teaching and Learning Literacy in the 21st Century: Lessons from Around the World (pp. 81-100). UNESCO. doi: 10.1163/9789004402379_005

Savage R, Georgiou G, Parrila R, Côté M.-F., Maiorino K., \& Dunn K. (2020). Interventions to improve the literacy skills of children at risk of dyslexia. In J. A. Washington, D.L. Compton \& P. McCardle (Eds.), Dyslexia: revisiting etiology, diagnosis, treatment, and policy (pp. 161-171). Brookes Publishing.

Savage, R., Georgiou, G., Parrila, R., Maiorino, K., Dunn, K., \& Burgos, G. (2020). The effects of teaching complex grapheme-phoneme correspondences: Evidence from a dual site cluster trial with at-risk grade 2 students. Scientific Studies of Reading, 24(4), 321-337. doi: 10.1080/10888438.2019.1669607

Schmalz, X., Marinus, E., Coltheart, M., \& Castles, A. (2015). Getting to the bottom of orthographic depth. Psychonomic Bulletin \& Review,22, 1614-1629. http://dx.doi.org/10.3758/s13423-015-0835-2.

Seymour, P. H. K., Aro, M., \& Erskine, J. M. (2003). Foundation literacy acquisition in European orthographies. British Journal of Psychology, 93, 143-174.

Smith, M. W., Brady, J. P., \& Clark-Chiarelli, N. (2008). Early Language and Literacy Classroom Observation K-3 tool (Research Edition). Baltimore: Paul H. Brookes. 
Snow, C. E. (2008). Cross-cutting themes and future research directions. In D. August \& T. Shanahan (Eds.), Developing reading and writing in second-language learners: Lessons from the report of the National Literacy Panel on languageminority children and youth (pp. 275-300). New York: Routledge.

Steacy, L. M., Elleman, A. M., Lovett, M. W., \& Compton, D. (2016). Exploring Differential Effects Across Two Decoding Treatments on Item-Level Transfer in Children With Significant Word Reading Difficulties: A New Approach for Testing Intervention Elements. Scientific Studies of Reading, 20, 283-295. doi:10.1080/10888438.2016.1178267

Tunmer, W. E., \& Chapman, J. W. (2012). Does set for variability mediate the influence of vocabulary knowledge on the development of word recognition skills?. Scientific Studies of Reading, 16(2), 122-140.

United Nations Educational, Scientific, and Cultural Organisation (2003). Education in a multilingual world (Vol. (ED-2003/WS/2)). France: UNESCO.

Vaughn, S., Cirino, P. T., Linan-Thompson, S., Mathes, P. G., Carlson, C. D., Hagan, E. C., . . Francis, D. J. (2006). Effectiveness of a Spanish intervention and an English intervention for English-language learners at risk for reading problems. American Educational Research Journal, 43, 449-487. doi: $10.3102 / 00028312043003449$

Wawire, B. A., \& Kim, Y-S, G. (2018): Cross-language transfer of phonological awareness and letter knowledge: Causal evidence and nature of transfer. Scientific Studies of Reading. doi: 10.1080/10888438.2018.1474882

Woodcock, R. W., McGrew, K. S., \& Mather, N. (2001). Woodcock Johnson III Test of 
Achievement. Itasca Illinois: Riverside Publishing. 


\section{Appendix A}

\section{Supplemental Interventions in Grade 1}

The two interventions that are presented in this study were researcher designed and consisted of three 30-minute out-of-class sessions per week and around 11 hours per child in duration. The sessions usually took place in a quiet room of the school, on a schedule agreed on with teachers of the participating classrooms. The lessons were run with groups of 3-4 children from the same class if possible. If not, children from more than one classroom were combined to form a group. Even if students were all considered weak readers, the groups were composed of children of varying levels of reading ability. Indeed, some students knew almost all the letter-sounds in English whereas others knew only one or two. Some students were able to blend 4 or 5 phonemes together whereas others could only blend two. Lessons were designed to allow for heavy differentiation, that is to say, the task was adapted to each student's ability level. For example, most struggling readers were given simpler words to decode (e.g. shorter words or words with only simple graphemes) whereas more advanced students were asked to decode more complicated words (e.g. longer words or words with multiple complex graphemes). The RAs' role in the differentiation was to ask each student to read words representing an acceptable challenge for them; words that were not too easy, but that were not impossible to read for them either. The interventions were run by research assistants (RAs), previously trained by either the researcher or the project coordinator. The training was undertaken in a two-hour meeting and role-play was used to make sure every RA was ready to carry out the intervention in schools. One week after the beginning of the intervention, the project coordinator met with the RAs to discuss the lessons of the week and to answer any further questions the RAs would have. The project coordinator and the researcher were also always available afterwards to answer any questions the RA might have. During the treatment integrity process, observers could also give direct feedback about the lesson to the RA, if required.

\section{The Direct Mapping and Set-for-Variability Intervention (DMSfV) Program.}

This intervention was designed to incorporate every aspect of an effective and intensive 
systematic synthetic phonics programs as well as the teaching of word reading strategies. Sessions were based on the following structure. Each session started with a review (2-5 minutes) and the teaching of a new GPC/reading strategy (5 minutes). Those activities were followed by a practice activity/game (10 minutes), as well as shared-book reading (10 minutes). The books used during shared reading were carefully selected to include a high density of the GPC taught during each lesson such that a GPC taught on a specific day was densely represented in shared texts given on that same day. The main goals of this program were to teach students letter-sounds, common digraphs and the principles of blending phonemes together, first with phonemes, and then from graphemes to phonemes. Common letter-sounds rules related to decoding in English were also taught to students (e.g. the silent e-rule). Lessons were organized as to include games in order to support students' motivation. For example, rolling dices to get letters to blend together, or using a snakes and ladders board game with words on each square. Lastly, one specific component of this intervention was the teaching of word reading strategies in relation to the concept of "setfor-variability" to help children decode words. Therefore, when students encountered unknown words they were unable to read, they were taught to try to match the decoded GPC chain to a word that sounded similar in their lexicon. They were also taught to identify graphemes that could be sounded out as more than one phoneme and to then try to sound out the word with the other possible sounds of that grapheme. This allowed them to check which of the pronunciation created a word that made sense for them. They were also supported through purely oral language tasks to understand what an RA-given regularized pronunciation of spoken regular and exception words might be. For example, in a session on naming body parts the pronunciation of 'ou' in 'shoulder' was regularized by an RA, and children were asked to try to work out what the word might really be, and told that this is a strategy for reading words when they do not make sense. In SfV activities there was a clear action or oral response required by children linking a spelling pronunciation to a known word, so teachers were able to see in 'real time' who had understood a task or an item in a task, and where children had not demonstrated understanding to revisit the item(s). SfV was not however formally measured in this study.

\section{Common or Best Practices (CBP) for Word Study Program.}


Like the DMSfV, the CBP intervention also aimed to teach phonics with effective teaching practices. It included activities and teaching practices that are known to be effective in the literature. The lessons' structure was always the same: review (2 minutes), letter-sound naming/grapheme phoneme correspondence teaching ( 3 minutes), phonics games (7 minutes), "sight word" reading (7 minutes) and shared-book reading (10 minutes). As for the DMSfV, to work on phonics, games such as rolling dices with letters and combining them (blending sounds) to form a word were used. The goal of the phonics activities was to help students to develop their phoneme blending skills and learn GPCs. The latter were not chosen to respect a predetermined order, but were taught in response to children's knowledge. Thus, RAs differentiated teaching so that students first learned all singletons and then progress to digraphs and English reading rules (i.e. magic "e" rule). Overall, approximately the same number of digraphs was taught in the CBP and the DMSfV. Games in which children had to segment phonemes and write words were also introduced later in the intervention. As in DMSfV, differentiation was used to adapt all tasks to students' ability level. Most struggling students would get easier words (based on length, GPC complexity, syllable structure) and stronger students, more complex words. This intervention was different from the DMSfV in multiple ways. First, "sight word" reading was introduced as part of the reading activities within each session. Words used during that phase of the lesson were drawn from a list of the 100 most frequent words in children's books (Vousden, Ellefson, Solity, \& Chater, 2011). Games such as snakes and ladders (with words on each square) were also used to sustain students' interest during this phase of the intervention. Another difference with the DMSfV is that books that were used in shared-book reading were not chosen depending on any specific GPC. The RAs would ask children to read only the words they considered they could read, following students' performance during the sessions. The number of words in books read by students thus increased during the interventions in relation with students' improving reading skills. For example, as the number of sight words recognized by students increased, the RAs would ask them to read it during shared-book reading. All words that were considered too complex (e.g. contained unknown GPCs) were read by the RAs. Lastly, no systematic teaching of word reading strategies such as set-for-variability was delivered in this program. 
Table A1

Summary table of both interventions

DMSfV $\quad$ CBP

Aspects That Are Distinct Across Interventions

- Taught GPCs were "directly mapped" to texts each day

- Taught more than one vowel digraph pronunciation

- Taught SfV as additional to phonic blending and to "flip" vowels

- NO teaching of sight words Daily teaching of sight words
- Taught GPCs were NOT "directly mapped" to texts each day

- Taught only one vowel digraph pronunciation

- $\quad$ NOT Taught SfV as additional to phonic blending or to "flip" vowels

- Daily teaching of sight words

Table A2

Shared characteristics of the two interventions

\begin{tabular}{ll}
\hline \multicolumn{1}{c}{ DMSfV } & CBP \\
\hline Length & Three 30-minute out-of-class sessions per week (total = 11 hours) \\
\hline Location & The sessions usually took place in a quiet room of the school \\
\hline Grouping & Groups of 3-4 children from the same class if possible. If not, \\
& children from more than one classroom were combined to form a \\
& group. The groups were composed of children of varying levels of \\
& reading ability. \\
\hline Teachers & The interventions were run by research assistants (RAs), previously \\
& trained by either the researcher or the project coordinator. \\
\hline
\end{tabular}


Differentiation Heavy differentiation; the task was adapted to each student's ability level.

GPCs Overall, approximately the same number of digraphs was taught in the CBP and the DMSfV

Table A3

Each session's structure

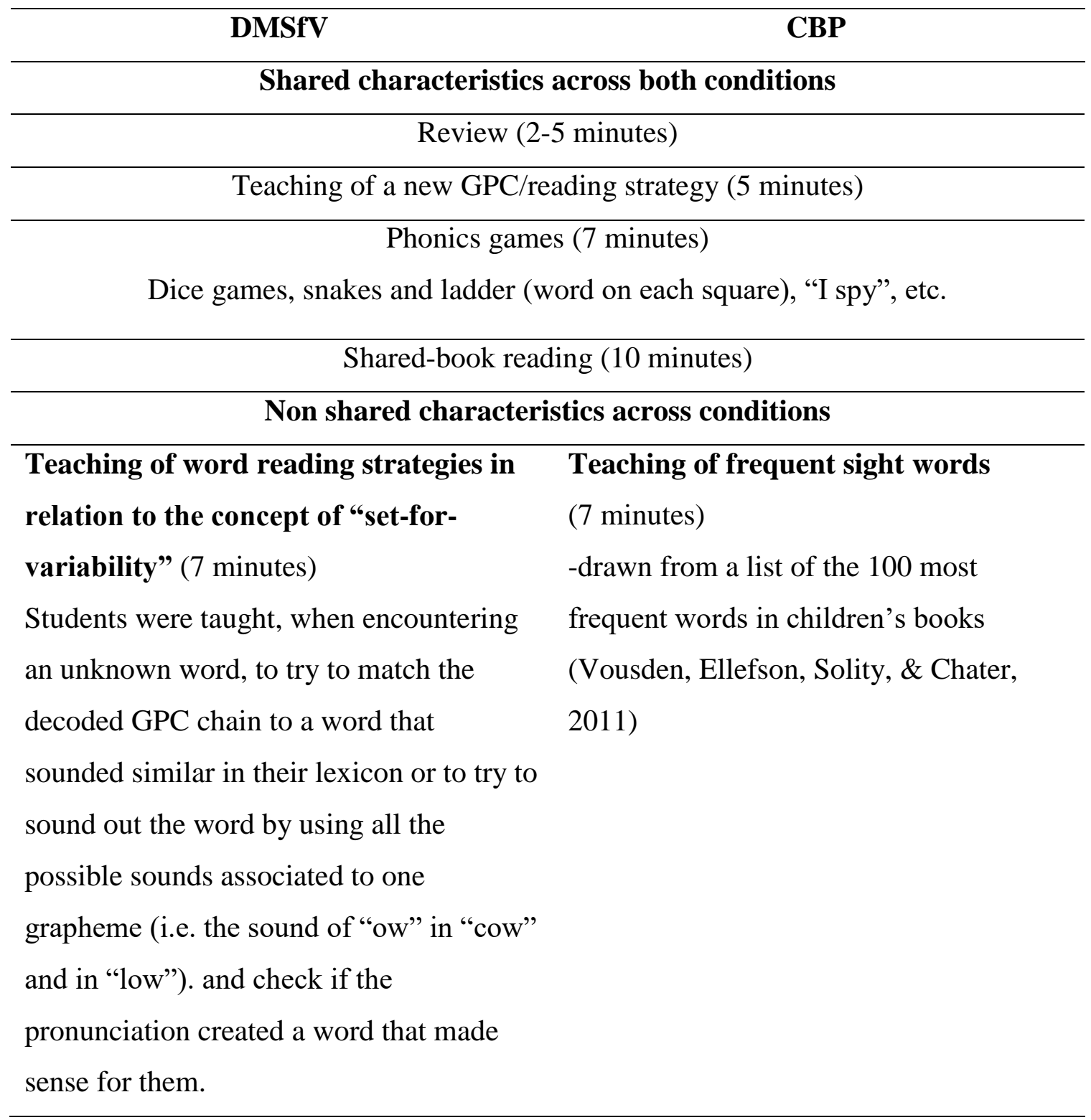

Appendix B 
French Immersion programs’ characteristics

In Quebec, The Charter of the French Language (Bill 101) (1977) requires all children to be educated entirely in French, except in certain very specific situations. Eligibility for such exception programs such as French immersion includes those whose family members undertook the major part of his or her elementary studies in English in Canada. Students with special authorization because of a serious learning disability or a serious family or humanitarian situation can also be educated in English and children of persons living in Quebec temporarily to study or work or children of members of the Canadian Armed Forces who are posted in Quebec.

Table B1

Descriptive Statistics for Schools' Characteristics

\begin{tabular}{ll}
\hline $\begin{array}{l}\text { Schools } \\
\text { (number of participants) }\end{array}$ & Immersion program \\
\hline
\end{tabular}

\begin{tabular}{lcc}
\hline & Kindergarten & Grade 1 \\
\hline DMSfV & & \\
$1(\mathrm{n}=3)$ & $100 \%$ French (Half-days) & $100 \%$ French (Half-days) \\
$2(\mathrm{n}=31)$ & $100 \%$ French & $50 \%$ French \\
$3(\mathrm{n}=6)$ & $40 \%$ French & (Whole week every two weeks) \\
$4(\mathrm{n}=13)$ & (90 minutes per day) & $40 \%$ French \\
& $50 \%$ French & (90 minutes per day) \\
& (Whole day every two days) & 50\% French
\end{tabular}

\section{CBP}

$5(\mathrm{n}=12)$

100\% French

$6(\mathrm{n}=3)$

100\% French

$50 \%$ French (Half-days)

$7(n=7)$

$40 \%$ French

(90 minutes per day)

$100 \%$ French

$40 \%$ French

$8(\mathrm{n}=11)$

40\% French

(90 minutes per day)

(90 minutes per day)

40\% French

(90 minutes per day) 
$9(\mathrm{n}=6)$

$10(\mathrm{n}=6)$
$50 \%$ French

(Whole day every two days)

$50 \%$ French

(Whole day every two days)
$50 \%$ French

(Whole day every two days) $50 \%$ French

(Whole day every two days) 